\title{
The Role of Occupational Stress and Emotional Intelligence in Working Health-Care and Medical Environments
}

\author{
Konstantinos Kanellakis ${ }^{1}$, Eirini Karakasidou1, Nikitas-Spiros Koutsoukis² \\ ${ }^{1}$ Department of Psychology, Panteion University, Athens, Greece \\ ${ }^{2}$ Department of Political Science \& International Relations, University of Peloponnese, Corinth, Greece \\ Email: *nkoutsou@uop.gr
}

How to cite this paper: Kanellakis, K., Karakasidou, E., \& Koutsoukis, N.-S. (2018). The Role of Occupational Stress and Emotional Intelligence in Working Health-Care and Medical Environments. Psychology, 9, 1516-1529.

https://doi.org/10.4236/psych.2018.96091

Received: April 10, 2018

Accepted: June 26, 2018

Published: June 29, 2018

Copyright $\odot 2018$ by authors and Scientific Research Publishing Inc. This work is licensed under the Creative Commons Attribution International License (CC BY 4.0).

http://creativecommons.org/licenses/by/4.0/

\section{(c) (i) Open Access}

\begin{abstract}
In this paper we investigate the effect of occupational stress and emotional intelligence on the performance of health-care employees, working in the operating room department. We expect, our results to prove useful to corresponding human resource departments for improving their practices and methods. We conducted a qualitative study with self-reported questionnaires measuring both, occupational stress and emotional intelligence. The survey was administered to health-care and medical employees in the 401 General Army Hospital of Athens. We then conducted descriptive data analysis and performed regression analysis with job performance as the dependent variable. We found that the level of emotional intelligence and occupational stress are positively correlated and they both affect performance. At the same time, gender does not seem to affect the level of emotional intelligence or the perception of occupational stress. Our regression model explains $17.6 \%$ of performance variability using the following predictor variables: the number of operations, the occupational stress and the emotional intelligence levels. However, the number of operations an employee participates in, affects the occupational stress perception. Finally, the level of emotional intelligence and annual sick leave seem to have a strong negative correlation. Hospital managers can use the findings of our research to monitor a number of variables related to emotional intelligence and occupational stress that seem to affect performance significantly.
\end{abstract}

\section{Keywords}

Occupational Stress, Emotional Intelligence 


\section{Introduction}

Greece is facing the most severe financial crisis in its recent history. The Greek economy has shrunk by more than $25 \%$ since mid-2008; unemployment during this period has risen to a steady $25 \%$, or about 1.2 million people. In addition, there was a fold increase in taxes. For the employees participating in the survey the average wage reduction was $24.3 \%$ before the effect of the increased taxation is taken into account. It follows that the financial crisis amplifies the effect and the perception of poor working conditions, it affects relationships among colleagues and presumably it also affects employee performance.

In this respect, a plethora of studies have demonstrated the strong relationship between emotional intelligence and occupational stress in relation to job performance. However, few studies have studied these above relationships in the health-care and medical domain and their effect on job performance, which are the scope of this study.

\section{Literature Review}

Occupational stress is a problem being studied for at least the past eighty five (85) years. However, most studies in the period 1929-1984 were aimed at traumatic or threatening events taking place in working environment. Nowadays, relevant research is mostly about chronic problems. Occupational stress is considered to be a part of working life, it is identifiable in many professions, and has many sources and effects on the mental and physical health of employees (Cooper \& Marshall, 1978; Cooper \& Payne, 1988; Dollard \& Winefield, 2002; Giga, Cooper, \& Faragher, 2003; Greenhaus \& Parasuraman, 1986; Ivancevich \& Matteson, 1980; Levi, 1990; Parasuraman \& Purohit, 2000). Further, it is presumed to affect even occupations previously considered to cause minimum stress, e.g. professors (Winefield \& Jarrett, 2001). Occupational stress is defined as the response individuals may exhibit when they face demanding work tasks and pressures, which do not match their knowledge and capabilities and challenge their ability to perform efficiently.

Likewise, increased attention has been given to Emotional Intelligence, as a matter of interest for both the scientific community, as well as the human resource management function, due to its implications in the occupational environment. From Thorndike (1920), who introduced the term "social intelligence", to Salovey \& Mayer (1990), who were among the first to use the term "emotional intelligence", up to Daniel Goleman (1995) who brought emotional intelligence to the awareness of the general public. Many surveys today support the importance of emotional intelligence in predicting performance. This body of work indicates that accomplishing working tasks is important, but cooperating, communicating, and dealing with conflicts, are the keys to operational survival and success. This defines emotional intelligence, as the capacity of a person to recognize their own and other people's emotions, to create motives and control appropriately the feelings and the relationships (Goleman, 1995). Accordingly, 
Goleman $(1995,1998)$ organizes the characteristics of emotional intelligence in five dimensions: self-awareness, self-regulation, behavioral motives, empathy and social capabilities.

In this paper we investigate the effect of occupational stress and emotional intelligence on the performance of health-care and medical domain employees (i.e. nurses, doctors, and health-care assistance providers), assigned to the operating room department. In particular we studied the level of emotional intelligence and the way employees experience occupational stress both separately and in tandem. We also investigate whether gender differences are likely to affect the level of emotional intelligence and the perception of occupational stress. Subsequently we investigated, which of the variables under consideration are useful performance predictors, and if the number of operations an employee participates in, affects occupational stress. Finally, we investigated the relation between emotional intelligence and the number of sick days per year. We acknowledge that performance measurement is multidimensional but in this study the only available proxy measure to performance was the number of days of sick leave every employee took through the year (2014-2015) and each of them voluntary stated.

\section{Method}

\subsection{Sample}

We distributed a total of 100 questionnaires with a return rate of $67 \%(\mathrm{~N}=67)$. 30 participants were males and 37 were females. The average years of experience across the sample were 11.9 years (with a standard deviation of 7.7 years). The results also revealed that $59.80 \%$ are married, $35.82 \%$ single and $4.48 \%$ divorced. Regarding the educational level $55.22 \%$ have a university degree, against $28.36 \%$ that have a lower qualification and $16.42 \%$ with a postgraduate (Master's level) degree (see appendix for Pie Chart 1).

Referring to the position of the employees in the operating room department, 29 are OR (Operating Room) nurses, 15 of are doctors, 12 of are health care and surgical practitioners and 8 are paramedics (see appendix for Pie Chart 2).

Referring to the income level, $16.42 \%$ stated a monthly income in the range of $600-900 €, 41.79 \%$ in the range of $900-1200 €, 29.85 \%$ in the range of $1200-$ $1500 €$ and $11.94 \%>1500 €$ (see appendix for Pie Chart 3). Finally, the mean number of operations for each employee was 37.94 operations/month $(\mathrm{SD}=$ 16.38 operations) and the mean number of sick leave was 2.69 days/year ( $\mathrm{SD}=$ 4.22 days).

\subsection{Psychometric Tools}

Considering that the purpose of our study was to investigate performance in accordance with occupational stress and the level of emotional intelligence, we decided to use two distinct sets of questions, integrated, in single questionnaires.

For the measurement of the occupational stress, we used the Occupational 
Roles Questionnaire-ORQ Inventory (Osipow \& Spokane 1987), which is part of the Occupational Stress Inventory-OSI (Osipow \& Spokane 1987), evaluates in which level the occupational environment is pressing and is consisted of 30 questions. The OSI contains three sections designed to measure occupational stress. The first section measures stress factors related with the occupational role of the person. The second part measures four types of strain: 1) occupational, 2) psychological, 3) interpersonal, 4) physical. The third part deals with coping resources (social support, entertainment, rationalization and self-care), all of which affect the management of the relationship among stress factors and the perceived strain. All items in the OSI employ a 4-point Likert-style response format ranging from "rarely or never true" (1) to "true most of the time" (4). The Occupational Roles Questionnaire (ORQ) contains six sub-scales measuring role overload, role insufficiency, role ambiguity, role boundary, responsibility, physical environment and measures occupational stress through a quantitative scale with a score between 30 and 120. The questionnaire had been translated in Greek and has sufficient psychometric properties (Cronbach alpha $=0.81$ ).

For the measurement of the employee's emotional intelligence, we used the Gala Emo Test (Galanakis, LoProto, Selioti, \& Stalikas, 2011). The test was developed according to Daniel Goleman's model, but has been adapted for Greece-based research. The test measures emotional intelligence as a personality attribute, especially applied in the occupational environment. The questionnaire is consists of 125 self-reported questions using a seven-level Likert scale, from: 1 being "totally disagree", to 7 being "totally agree". The Gala Emo test consists of five subsections, each of which refers to a dimension of emotional intelligence according to the model of Daniel Goleman (1995). Every subsection consists 25 questions. The dimensions are (a) self-awareness, (b) self-regulation, (c) behavioral motives, (d) empathy and (e) social capabilities. The test includes many reversed items in order to avoid polarity and social acceptable answers. The level of emotional intelligence is measured through a quantitative scale and the highest score is 875 . The test can be used to measure each dimension independently, with highest score per dimension being 175 . Moreover, it has satisfying psychometric properties (Cronbach alpha $=0.89$ ). For this research paper, we used the total score of emotional intelligence.

We analyzed the data using statistical software. We conducted descriptive statistical analysis for the sample's characteristics, t-tests for evaluating independence (e.g. between genders). Further we analyzed statistical correlation and carried out a regression analysis with sick leave as a proxy for "performance" and the dependent variable, with emotional intelligence and occupational stress as the independent variables. The statistical significance level was 0.05 .

\section{Results}

The descriptive statistics for the major study variables are presented in Table 1.

Subsequently we tested for statistically significant difference among the 
Table 1. Descriptive statistics for the study variables.

\begin{tabular}{ccccccc}
\hline & $\begin{array}{c}\text { Mean } \\
\text { M }\end{array}$ & $\begin{array}{c}\text { Median } \\
\text { Md }\end{array}$ & $\begin{array}{c}\text { Mode } \\
\text { Mo }\end{array}$ & $\begin{array}{c}\text { St. Deviation } \\
\text { SD }\end{array}$ & $\begin{array}{c}\text { Skewness } \\
\text { Sk }\end{array}$ & $\begin{array}{c}\text { Kurtosis } \\
\text { Ku }\end{array}$ \\
\hline $\begin{array}{c}\text { Occupational } \\
\text { stress (30 - 120) }\end{array}$ & 63.39 & 64 & 64 & 7.77 & -.376 & .287 \\
EQ $(125-875)$ & 585.66 & 589 & 589 & 46.88 & -.127 & -.230 \\
\hline
\end{tabular}

genders, using the Independent Samples t-test. We found, no significant differences when considering the variables of occupational stress and emotional intelligence $(\mathrm{t}=.105, p=.916)$. This suggests that there is no difference among men and women in the level of emotional intelligence in the working environment, but also that there is no significant difference in the way the two genders experience occupational stress $(\mathrm{t}=-472, p=.638)$ (Table 2).

We then proceeded to test for statistical correlation. First, between occupational stress and emotional intelligence using the Pearson correlation coefficient. As seen in Table 3, there is a moderate negative correlation between occupational stress and emotional intelligence $(\mathrm{r}=-.282, p=.021)$. Hence, employees, who have a higher level of emotional intelligence, may experience less occupational stress and vice versa.

Then we tested the correlation between the number of operations and occupational stress. As shown in Table 3, there is a moderate positive correlation $(\mathrm{r}=$ $0.273, p=0.03$ ). Thus, an increase in the number of operations the employees participate in, may lead to an increase in the level of occupational stress experienced.

We completed the correlation analysis with the level of emotional intelligence and annual days of sick leave. As shown in Table 3, there is a moderate negative correlation ( $\mathrm{r}=-0.257, p=0.044)$. Accordingly, an increase in the level of emotional intelligence, may lead to a decrease in the number of annual days of sick leave.

We used multiple linear regression to examine if the variables: "number of operations" an employee participates in, and his/her level of "emotional intelligence" and "occupational stress", were likely to predict performance, using annual days of sick leave as a proxy measure for performance. Performance is the dependent variable and number of operations, emotional intelligence, and occupational stress are the independent variables. The model produced explains $17.6 \%$ of performance observations as depicted in Table 4 .

\section{Discussion}

Our findings suggest that there is a moderate negative correlation between occupational stress and emotional intelligence, suggesting that that people with higher emotional intelligence tend to experience less occupational stress. This confirms similar findings by Seligman \& Csikszenmihalyi (2000). Additionally, in a study about Occupational stress and Emotional Intelligence among Greek bank employees, it was observed that employees who manage other people's 
Table 2. T-test for independent samples for gender differences.

\begin{tabular}{ccccc}
\hline \multicolumn{5}{c}{ Gender } \\
\hline & Men & Women & & \\
& M (SD) & M (SD) & $t$ & $p$ \\
\hline Occupational stress & $63.50(8.06)$ & $63.30(7.64)$ & .105 & .916 \\
Emotional intelligence & $582.63(53.52)$ & $588.11(41.33)$ & -.472 & .638 \\
\hline
\end{tabular}

Table 3. Pearson r correlations for all major study variables.

\begin{tabular}{|c|c|c|c|c|}
\hline & $\begin{array}{c}\text { No-operations } \\
\mathrm{R}\end{array}$ & $\begin{array}{c}\text { Sick leave } \\
\text { R }\end{array}$ & $\begin{array}{c}\text { Emotional } \\
\text { Intelligence } \\
\mathrm{R}\end{array}$ & $\begin{array}{c}\text { Occupational Stress } \\
\text { R }\end{array}$ \\
\hline No-operations/month & 1 & .240 & -137 & $273^{*}$ \\
\hline Sick leave/year & & 1 & $-.257^{\star}$ & -.149 \\
\hline Emotional intelligence & & & 1 & $-.282^{*}$ \\
\hline Occupational stress & & & & 1 \\
\hline
\end{tabular}

$P^{\star}<.05$.

Table 4. Multiple regression analysis for the prediction of performance (sick leave).

\begin{tabular}{cccccc}
\hline PERFORMANCE & \multicolumn{1}{c}{ Beta } & $B$ & $t$ & $F$ & $R^{2}$ \\
\hline Predictors & & & & & \\
& & & & \\
No operations & .283 & .075 & $2.181^{*}$ & & \\
Emotional intelligence & -.269 & -.025 & $-2.058^{*}$ & \\
Occupational stress & -.310 & -.167 & $-2.328^{*}$ & \\
Gender & .005 & .042 & .039 & \\
\hline
\end{tabular}

${ }^{*} \mathrm{p}<.05$.

emotions and tend give in to these emotions, were more likely to experience occupational stress. Optimistic employees, who were able to manage their personal emotions adequately, were more likely to use stress management strategies. On the other hand, the opposite seemed true for employees who were unable to manage their personal emotions (Belias, Koustelios, Koutiva, \& Zournatzi, 2013).

With respect to gender and its relation to occupational stress and emotional intelligence, our study indicates no significant differences in the level of emotional intelligence between the two genders or in the way the genders experience occupational stress. However, these findings contrast the research of Rahim \& Malik (2010), who investigated the effect of demographic factors in relation with emotional intelligence on bank employees' performance. In particular, they found out that women reported higher levels of emotional intelligence. Additional research (Extremera et al., 2006) suggests that emotional intelligence is positively correlated to age while, women exhibit higher levels of emotional in- 
telligence compared to men. In another study by Petrides \& Furnham (2000) on gender differences, they found out that female participants had better social skills than men, however, generally men were measured to have higher emotional intelligence than women. In the study by Schutte et al. (1998) women seem to have significantly higher emotional intelligence than men. The gender seemed to affect the emotional intelligence of employees, in the way they use their emotions, indicating that women believed that positive emotions might lead to new ideas and improvements in the occupational environment more than men did. However, considering the factor of emotional intelligence, (Aftab \& Khatoon, 2012) support that women are more likely to perceive non-verbal messages, recognize their and other people's emotions more easily than men and are more supportive to other people's problems, which can be a possible explanation, why women are considered to be more sentimental than men.

On the other hand, the cross-cultural study of Miller et al. (2000) among managers from the United Kingdom, the United States of America, South Africa and Taiwan has similar results to ours. More specifically, the experience of occupational stress was correlated with organizational climate but not with gender. Moreover, men were in better mental and physical well-being than women in UK and South Africa in comparison to the UK, and used different stress-coping strategies. In the Greek occupational environment, research by Galanakis et al. (2009) and Antoniou et al. (2006) indicates higher occupational stress levels in female than male employees in the field of education. In the study about Occupational stress and Emotional Intelligence among Greek bank employees, there were no significant differences in the way the two gender experience stress (Belias, Koustelios, Koutiva, \& Zournatzi, 2013).

Taking into account the factor of performance (based on annual days of sick leave), we found that the variables a) number of operations an employee participates in, b) his/her level of emotional intelligence and c) occupational stress, may account for a part of it (17.6\%). In a research of Jones, Huxtable, Hodgson, and Price (2003) it was estimated that each employee took annually 28.5 days of sick leave and that stress was the second main cause of work-related ill health. Sullivan \& Bhagat (1992) supported that there are four main hypotheses tests between stressors and work performance. The first indicates that performance is better when stressors are experienced in a moderate way. The second deducts that work performance and occupational stress have a positive linear relationship that associates stressors with "challenge" (Meglino, 1977). Arsenault \& Dolan (1983) and Kahn \& Long (1988) support this view with their studies. The third hypothesis claims that stressors and work performance have a negative linear relationship (Iaffaldano \& Muchinsky, 1985; Motowidlo et al., 1986). The fourth indicates that there is no relation between performance and stress (see Matteson, Ivancevich, \& Smith, 1984; Orpen \& Welch, 1989). However, the majority of research literature supports the negative association (e.g., Allen, Hitt, \& Greer, 1982; Greer \& Castro, 1986; Iaffaldano \& Muchinsky, 1985; Westman \& 
Eden, 1991, 1996). Motowidlo et al. (1986) in a study of nurses confirm the negative relationship between occupational stress and performance. Likewise, Iaffaldano \& Muchinsky (1985) and Steen, Firth, \& Bond (1998) had similar findings regarding nurses. Furthermore, in a survey in USA, where 28,000 employees of 215 organizations participated, it was found that in the United States stress at work was related with poor work performance, acute and chronic health problems and employees' burnout (Ivancevich et al., 1990; Kohler \& Kamp, 1992). Stress damages performance, and according to the negative linear relation hypothesis, increasing stress level causes more damage to performance (Pincherle, 1972; Jex, 1998). However, from the positive linear hypothesis viewpoint, when there is no feeling of challenge (i.e. stress) (Hatton et al., 1995; Kahn \& Long, 1988), consequently performance is low (Meglino, 1977). Even though empirical results support the negative relation between occupational stress and performance (Friend, 1982; Jamal, 1984; Westman \& Eden, 1991; Westman \& Eden, 1996), there is also the inverted-U theory that connects the negative and positive linear models and suggests that increasing stress till a specific point can be beneficial for performance. After that point, stress is disastrous. As a result, there are two stress studies, which support the inverted-U theory (Anderson, 1976; Srivastava \& Krishna, 1991). What is more, the nature and effects of occupational stress are causing health problems to employees (that is why they ask for sick leave) and also cause a business cost (Shanton et al., 2001). In the end, considering the transactional model (Fried et al., 2008; Lazarus \& Folkman, 1984), employees experiencing more stress, probably damage their physical and psychological health and perform worse. These findings confirm previous studies (Clarke \& Cooper, 2000), in defining the relation between occupational stress and performance. Accordingly it was found that occupational stress affects nurses' job performance, thus compromising nursing care and putting lives of patients at risk.

In a research among 3000 CEOs and managers, Daniel Goleman indicated that emotional intelligence can predict the organizational climate, the success, the profit and the performance of the organization. Furthermore, Seligman \& Csikszenmihalyi (2000) deduct that positive affect supported professionals in health-care and medical domain, who worked with HIV patients, to experience low levels of stress and suggested (2000a) that psychological health and the well-being are improved with positive emotions. Worldwide, there is intense interest from many organizations for the measurement and development of emotional intelligence of their employees, in an effort to improve performance by developing a higher level of emotional intelligence (Platsidou, 2010). The positive correlation between stress and 1) workload (number of operations they participate in this study), 2) employees physical and mental health status, has been confirmed by several studies (Burchell, 2002; Nishitani \& Sakakibara, 2010), which explains the predictable effect of workload on performance.

Another important result deducted from the present study is that the relation 
between the number of operations an employee participates in (i.e. workload) and occupational stress is positive and statistically significant. Taking into account a survey about occupational stress, job satisfaction and job performance among hospital nurses in Kampala, Uganda, it was deducted that stress is the outcome of high work demands and low or minimum decision making capabilities delegated to employees. So, the level of stress might increase in demanding jobs with low control from employees. Many additional studies confirm the positive correlation between workload and stress (Burchell, 2002; Nishitani \& Sakakibara, 2010).

Finally, the level of emotional intelligence and annual days of sick leave seem to exhibit a moderate negative correlation. Likewise, Salovey \& Mayer, 1990 and Mayer \& Salovey, 1995 indicated that higher levels of emotional intelligence might lead in a better psychological and physical well-being. What is more, Salovey, Stroud, Woolery, \& Epel (2002) connected the high levels of emotional intelligence with better psycho-physiological reactions against stress. Moreover, Salovey, Bedell, Detweiler, \& Mayer (1999) found out that people, who are able to control their emotions are healthier, because of their perception and appraisal of the emotional states, their ability to know how and when to express themselves and can handle their emotional condition. So, there is little doubt that emotional intelligence contributes positively to both, physical and psychological well-being (Tsaousis \& Nikolaou, 2005).

\section{Conclusion-Further Research}

The results of our study concern a representative sample of operating room department employees. However, they should be carefully interpreted. Although our findings are in line and reaffirm a respectable number of studies worldwide we note that there are also several studies with contradicting outcomes.

We investigated the level of emotional intelligence and the way employees experience occupational stress in the operating room independently and in relation to each other. Our findings results indicate that there is a moderate negative correlation between occupational stress and emotional intelligence.

Further, we examine whether gender differences are likely to affect the level of emotional intelligence and the experience of occupational stress. We found that there is no significant difference among men and women in the level of emotional intelligence in the working environment, but also that there is no significant difference in the way the two genders experience occupational stress. Without doubt, in our study, emotional intelligence cannot be used to differentiate between the two genders. However, considering the controversy of findings in other studies, further research about emotional intelligence for both men and women is necessary, especially for this occupational environment.

In general, our study supports the view that both occupational stress and emotional intelligence should be taken into account in order to improve performance. Therefore we recommend, that hospital managers develop the appropri- 
ate working conditions for the employees occupied in their organizations in order to increase emotional intelligence and reduce occupational stress.

Moreover, in this study was made an effort to find out, which of the variables being examined are predicting performance. Specifically, the model explains $17.6 \%$ of performance using a) the number of operations b) the occupational stress and c) emotional intelligence. But while occupational stress, workload and emotional intelligence may predict part of the performance, there is no doubt that there are more factors which need to be identified and studied.

Overall we can safely reaffirm that reducing occupational stress and excessive work demands while putting the effort to increase the level of emotional intelligence of employees in the healthcare working communities, performance can be improved. It follows that, the application of motivation strategies and effective communication and recognition techniques among the organization's members by human resources departments, such results are definitely going to be improved.

In completing our analysis we investigated whether the number of operations an employee participates in, affects the perception of occupational stress. We found that workload (number of operations) is moderately correlated to occupational stress. Thus employees will perform more efficiently and experience lower levels of occupational stress in a working environment, if they have lower workloads, or if their emotional intelligence is improved, e.g. by encouraging mutual respect of individual needs and emotions among peers and colleagues. Thus, we reaffirm that the development of an employee friendly occupational environment should be the target of the best-performing organizations, including healthcare. Caring for every employee's personal needs and making use of everyone's unique capabilities and skills, should be the cornerstones of an efficiently working organization. Overall we believe that this kind of surveys would be more beneficial if carried out at the national level, so that the occupational stress and emotional intelligence among healthcare employees can be studied in depth. We anticipate our small-scale field study to serve as a cornerstone in this direction.

\section{References}

Aftab, M., \& Khatoon, T. (2012). Demographic Differences and Occupational Stress of Secondary School Teachers. European Scientific Journal, 8, 1857-1881.

Allen, R. D., Hitt, M. A., \& Greer, C. R. (1982). Occupational Stress and Perceived Organizational Effectiveness in Formal Groups: An Examination of Stress Level and Stress Type. Personnel Psychology, 35, 359-370. https://doi.org/10.1111/j.1744-6570.1982.tb02201.x

Anderson, C. R. (1976). Coping Behaviors as Intervening Mechanisms in the Inverted-U Stress-Performance Relationship. Journal of Applied Psychology, 61, 30-34. https://doi.org/10.1037/0021-9010.61.1.30

Antoniou, A. S., Polychroni, F., \& Vlachakis, A. N. (2006). Gender and Age Differences in Occupational Stress and Professional Burnout between Primary and High-School Teachers in Greece. Journal of Managerial Psychology, 21, 682-690. 
https://doi.org/10.1108/02683940610690213

Arsenault, A., \& Dolan, S. (1983). The Role of Personality, Occupation and Organization in Understanding the Relationship between Job Stress, Performance and Absenteeism. Journal of Occupational Psychology, 56, 227-240.

https://doi.org/10.1111/j.2044-8325.1983.tb00130.x

Belias, D., Koustelios, A., Koutiva, M., \& Zournatzi, E. (2013). Occupational Stress and Emotional Intelligence among Greek Bank Employees. International Journal of Human Resource Studies, 3, 79. https://doi.org/10.5296/ijhrs.v3i4.4372

Burchell, B. (2002). The Prevalence and Redistribution of Job Insecurity and Work Intensification. In B. Burchell, D. Ladipo, \& F. Wilkinson (Eds.), Job Insecurity and Work Intensification (pp. 61-76), London: Routledge.

Clarke, S. G., \& Cooper, C. L. (2000). The Risk Management of Occupational Stress. Health Risk \& Society, 2, 173-187. https://doi.org/10.1080/713670158

Cooper, C. L., \& Marshall, J. (1978). Sources of Managerial Stress and White Collar Stress. In C. L. Cooper \& R. Payne (Eds.), Stress at Work, New York: Wiley.

Cooper, C. L., \& Payne, R. (Eds.) (1988). Causes, Coping and Consequences of Stress at Work. England: Wiley.

Dollard, M. F., \& Winefield, A. H. (2002). Mental Health: Overemployment, Underemployment, Unemployment and Healthy Jobs. Australian e-Journal for the Advancement of Mental Health, 1, 170-195. https://doi.org/10.5172/jamh.1.3.170

Extremera, N., Fernandez-Berrocal, P., \& Salovey, P. (2006). Spanish Version of the Mayer-Salovey-Caruso Emotional Intelligence Test (MSCEIT). Version 2.0: Reliabilities, Age and Gender Differences. Psichothema, 18, 42-48.

Fried, Y., Shirom, A., Gilboa, S., \& Cooper, C. L. (2008). The Mediating Effects of Job Satisfaction and Propensity to Leave on Role Stress-Job Performance Relationships: Combining Meta-Analysis and Structural Equation Modeling. International Journal of Stress Management, 15, 305-328. https://doi.org/10.1037/a0013932

Friend, K. E. (1982). Stress and Performance: Effects of Subjective Work Load and Time Urgency. Personality Psychology, 35, 623-633. https://doi.org/10.1111/j.1744-6570.1982.tb02214.x

Galanakis, M., LoProto, K., Selioti, K., \& Stalikas, A. (2011). The Standardization of an Original Scale for the Measurement of Emotional Intelligence. Notebooks of Data Analysis, 12, 83-111.

Galanakis, M., Stalikas, A., Kallia, H., Karagianni, C., \& Karela, C. (2009). Gender Differences in Experiencing Occupational Stress: The Role of Age, Education and Marital Status. Stress and Health, 25, 397-404. https://doi.org/10.1002/smi.1248

Giga, S. I., Cooper, C. L., \& Faragher, B. (2003). The Development of a Framework for a Comprehensive Approach to Stress Management Interventions at Work. International Journal of Stress Management, 10, 280-296. https://doi.org/10.1037/1072-5245.10.4.280

Goleman, D. (1995). Emotional Intelligence; Why It Can Matter More than IQ. London: Bloomsbury.

Goleman, D. (1998). Working with Emotional Intelligence. New York: Bantam.

Greenhaus, J. H., \& Parasuraman, S. (1986). Vocational and Organizational Behavior, 1985: A Review. Journal of Vocational Behavior, 29, 115-176. https://doi.org/10.1016/0001-8791(86)90001-1

Greer, C. R., \& Castro, M. A. D. (1986). The Relationship between Perceived Unit Effectiveness and Occupational Stress: The Case of Purchasing Agents. The Journal of Applied Behavioral Science, 22, 159-175. https://doi.org/10.1177/002188638602200208 
Hatton, C., Brown, R., Caine, A., \& Emerson, E. (1995). Coping Strategies and Stress-Related Outcomes among Direct Care Staff in Staffed House for People with Learning Disabilities. Mental Handicap Research, 8, 252-271. https://doi.org/10.1111/j.1468-3148.1995.tb00161.x

Iaffaldano, M. T., \& Muchinsky, P. M. (1985). Job Satisfaction and Job Performance: A Meta-Analysis. Psychological Bulletin, 97, 251-273. https://doi.org/10.1037/0033-2909.97.2.251

Ivancevich, J. M., \& Matteson, M. T. (1980). Optimizing Human Resources: A Case for Preventive Health and Stress Management. Organizational Dynamics, 9, 5-25. https://doi.org/10.1016/0090-2616(80)90037-6

Ivancevich, J. M., Matteson, M. T., Freedman, S. M., \& Phillips, J. S. (1990). Worksite Stress Management Interventions. American Psychologist, 45, 252-261. https://doi.org/10.1037/0003-066X.45.2.252

Jamal, M. (1984). Job Stress and Job Performance Controversy: An Empirical Assessment. Organ. Organizational Behavior and Human Performance, 33, 1-21. https://doi.org/10.1016/0030-5073(84)90009-6

Jex, S. M. (1998). Stress and Job Performance. London: Sage Publications.

Jones, J. R., Huxtable, C. S., Hodgson, J. T., \& Price, M. J. (2003). Self-Reported Work-Related Illness in 2001/02: Results from a Household Survey. Health and Safety Executive.

Kahn, S. E., \& Long, B. C. (1988). Work-Related Stress, Self-Efficacy, and Wellbeing of Female Clerical Workers. Counselling Psychology Quarterly, 1, 145-153. https://doi.org/10.1080/09515078808254197

Kohler, S., \& Kamp, J. (1992). American Workers under Pressure. Technical Report, Saint Paul, MN: St Paul Fire and Marine Insurance Company.

Lazarus, R. S., \& Folkman, S. (1984). Stress, Coping, and Appraisal. New York, NY: Springer.

Levi, L. (1990). Occupational Stress: Spice of Life or Kiss of Death? American Psychologist, 45, 1142-1145. https://doi.org/10.1037/0003-066X.45.10.1142

Matteson, M. T., Ivancevich, J. M., \& Smith, S. V. (1984). Relation of Type A Behavior to Performance and Satisfaction among Sales Personnel. Journal of Vocational Behavior, 25, 203-214. https://doi.org/10.1016/0001-8791(84)90044-7

Mayer, J. D., \& Salovey, P. (1995). Emotional Intelligence and the Construction and Regulation of Feelings. Applied \& Preventive Psychology, 4, 197-208. https://doi.org/10.1016/S0962-1849(05)80058-7

Meglino, B. M. (1977). Stress and Performance: Are They Always Incompatible? Supervisory Management, 22, 2-12.

Miller, K., Greyling, M., Cooper, G., Lu, L., Sparks, K., \& Spector, P. E. (2000). Occupational Stress and Gender: Across-Cultural Study. Stress Medicine, 16, 271-278. https://doi.org/10.1002/1099-1700(200010)16:5<271::AID-SMI862>3.0.CO;2-G

Motowidlo, S. J., Packard, J. S., \& Manning, M. R. (1986). Occupational Stress: Its Causes and Consequences for Job Performance. Journal of Applied Psychology, 71, 618-629. https://doi.org/10.1037/0021-9010.71.4.618

Nishitani, N., \& Sakakibara, H. (2010). Job Stress Factors, Stress Response, and Social Support in Association with Insomnia of Japanese Male Workers. Industrial Health, 48, 178-184. https://doi.org/10.2486/indhealth.48.178

Orpen, C., \& Welch, M. (1989). Stress and Work Attitudes among Australian Nurses: An Empirical Study. Psychological Studies, 34, 214-215. 
Osipow, S. H., \& Spokane, A. R. (1987). Manual for the Occupational Stress Inventory. Odessa, FL: Psychological Assessment Resources.

Parasuraman, S., \& Purohit, Y. S. (2000). Distress and Boredom among Orchestra Musicians: The Two Faces of Stress. Journal of Occupational Health Psychology, 5, 74-83. https://doi.org/10.1037/1076-8998.5.1.74

Petrides, K. V., \& Furnham, A. (2000). Gender Differences in Measured and Self-Estimated Trait Emotional Intelligence. Sex Roles, 42, 449-461. https://doi.org/10.1023/A:1007006523133

Pincherle, G. (1972). Assessment of the Relationship between Stress and Work Performance. Journal of the Royal Society of Medicine, 65, 321-324.

Rahim, S. H., \& Malik, M. I. (2010). Emotional Intelligence and Organizational Performance: A Case Study of Banking Sector in Pakistan. International Journal of Business and Management, 5, 191-197.

Salovey, P., \& Mayer, J. D. (1990). Emotional Intelligence. Imagination, Cognition \& Personality, 9, 185-211. https://doi.org/10.2190/DUGG-P24E-52WK-6CDG

Salovey, P., Stroud, L. R., Woolery, A., \& Epel, E. S. (2002). Perceived Emotional Intelligence, Stress Reactivity, and Symptom Reports: Further Explorations Using the Trait Meta-Mood Scale. Psychology and Health, 17, 611-627. https://doi.org/10.1080/08870440290025812

Schutte, N. S., Malouff, J. M., Hall, L. E., Haggerty, D. J., Cooper, J. T., Golden, C. J., \& Dornheim, L. (1998). Development and Validation of a Measure of Emotional Intelligence. Personality and Individual Differences, 25, 167-177. https://doi.org/10.1016/S0191-8869(98)00001-4

Seligman, M. E. P., \& Csikszentmihalyi, M. (2000). Positive Psychology: An Introduction. American Psychologist, 55, 5-14.

https://doi.org/10.1037/0003-066X.55.1.5

Shanton, J. M., Balzer, W. K., Smith P. C., Parra L. F., \& Ironson, G. (2001). A General Measure of Work Stress: The Stress-in-General Scale. Educational and Psychological Measurement, 61, 866-877. https://doi.org/10.1177/00131640121971455

Srivastava, A. K., \& Krishna, A. (1991). A Test of Inverted U Hypothesis of Stress Performance Relationship in the Industrial Context. Psychological Studies, 36, 34-38.

Steen, N., Firth, H. W., \& Bond, S. (1998). Relation between Work Stress and Job Performance in Nursing: A Comparison of Models. Structural Equation Modeling: A Multidisciplinary Journal, 5, 125-142. https://doi.org/10.1080/10705519809540096

Sullivan, S. E., \& Bhagat, R. S. (1992). Organizational Stress, Job Satisfaction and Job Performance: Where Do We Go from Here? Journal of Management, 18, 353-374. https://doi.org/10.1177/014920639201800207

Thorndike, E. L. (1920). Intelligence and Its Uses. Harper's Magazine, 140, 227-235.

Tsaousis, I., \& Nikolaou, I. (2005). Exploring the Relationship of Emotional Intelligence with Physical and Psychological Health Functioning. Stress and Health, 21, 77-86. https://doi.org/10.1002/smi.1042

Westman, M., \& Eden, D. (1991). Implicit Stress Theory: The Spurious Effects of Stress on Performance Ratings. Journal of Social Behavior and Personality, 6, 127-170.

Westman, M., \& Eden, D. (1996). The Inverted-U Relationship between Stress and Performance: A Field Study. Work \& Stress, 10, 165-173. https://doi.org/10.1080/02678379608256795

Winefield, A. H., \& Jarrett, R. (2001). Occupational Stress in University Staff. International Journal of Stress Management, 8, 285-298. 


\section{Appendices}

\section{Graphics}

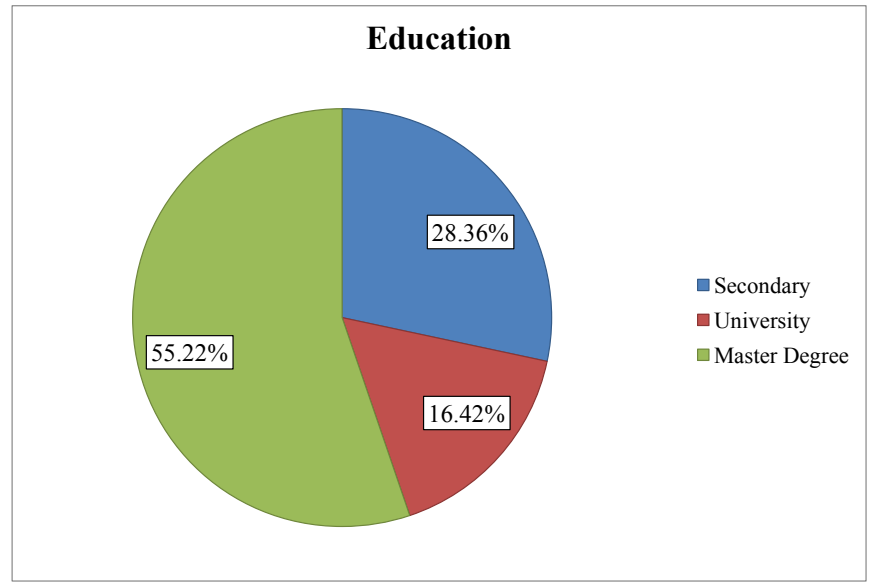

Pie Chart 1. Percentage of educational status level.

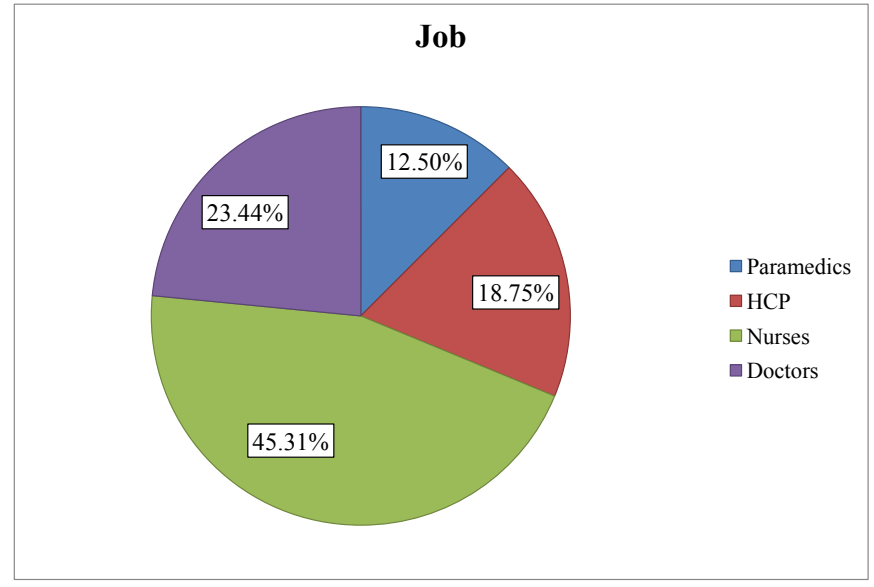

Pie Chart 2. Occupations of employees participate in the sample.

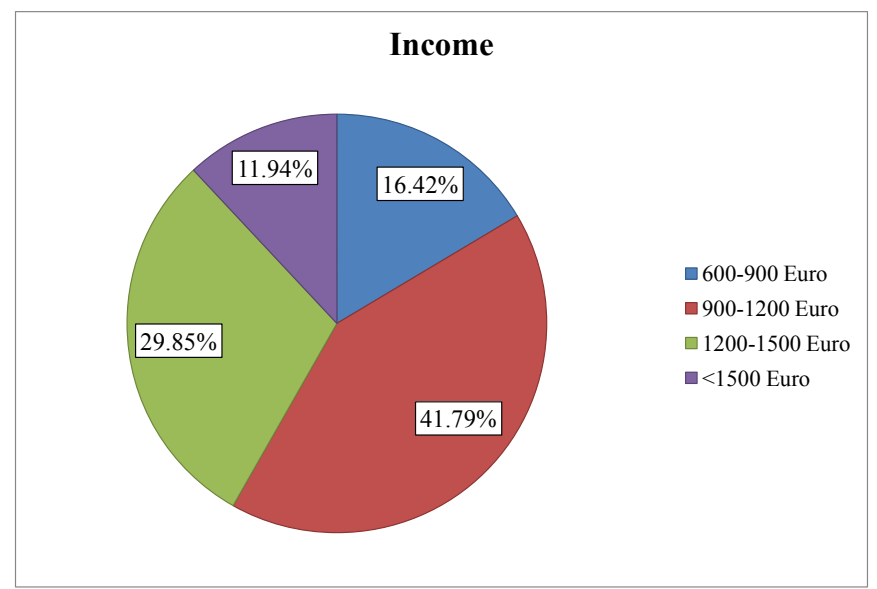

Pie Chart 3. Percentages of the income's level. 